\title{
How by applying TQM, higher educational programs enriches?
}

\author{
Raissi, s. \\ Raissi@azad.ac.ir
}

\author{
Islamic Azad University \\ Tehran South Branch
}

\author{
Javid, $\mathbf{N}$. \\ Javid@azad.ac.ir
}

\begin{abstract}
:
TQM is a philosophy and system for continuously improving the services and/or products offered to customers. It can help a university provide better service to its primary customers-students and professors. The continuous improvement focus of TQM is a fundamental way of fulfilling the accountability requirements common to educational reform.

Operating a no-fear TQM system with a focus on continuous growth and improvement offers more excitement and challenge to students and teachers than a "good-enough" learning environment can provide.

This paper tends to give an overview about Total Quality Management abbreviated by TQM and its core concept due to implement it in universities in order to enrich the higher educational programs. Every body must know, TQM in Education is a timely tool, which must be clearly understood, adopted and implemented as soon as possible.
\end{abstract}

Key words: Total Quality Management in education, Continuous improvement and Higher education management.

\section{What is TQM?}

The core concepts of TQM as listed [1] are as follows:

\section{1- Customer focus}

TQM takes to heart the old saying " the customer is king". Every organization has a customer. There are two types of customers, one is internal and the other is external. The external customer is the person who purchases the product or service. Universities have a variety of customers. Students take classes, consume meals, sleep in residence halls, buy books and use many services for which they pay tuition and fees. The student certainly fits the definition of the word customer. Parents, employer, community, the state government, and the society at large constitute the external clients On the other hand, the internal customer uses the products provided by the other groups. Teacher, non-academic staff, principal, manager and managing committee form the internal clients. The businesses and professions that employ the graduates are also external customers. This shows that each and every work group is associated with the value of the product being made for the customer. This would lead workers to attain knowledge about the voice of customer (customer's needs and wants) and let them work accordingly.

The customer's needs have to be accurately determined and this is an important aspect of quality control. The knowledge of the customer's needs should be attained in the initial stages rather than later because it would save both time and investment. There would be a time saving and this will ultimately lead to a fair profit.

\section{2- Management commitment to TQM}

The top management (senior administrators) must develop a complete understanding of what TQM is and how they plan to achieve it.

Managing continuous movement toward progressively higher quality standards depends on defining those standards. If a TQM steering committee is formed in a university, it should 
determine the answer to this question--Does the university have a clear, customer-focused mission statement and a functioning process for divisions and/or departments translating this statement into exit outcomes for graduates? If the answer is "no", that problem must be addressed with local, state, national, and employer standards. These standards should emphasize developing students' abilities to solve real-life problems rather than just memorizing subject matter. The latter does not represent quality for either students or professors.

\section{3- Process/ system orientation}

The TQM emphasis on satisfying internal customers is strongly related to its focus on process and systems. The theory is that only by concentrating on understanding and improving the teaching and learning processes by which things are done is there any hope of improving and organization's efficiency and ultimate products.

\section{4- Continuous process improvement}

A process is simply a sequence of tasks, which together produce a product or service. There are various techniques for doing this. The teams are made to study the problem during the process and then execute that by implementing solutions. The supplier is also a part of the production process. There are many methods in which the supplier is also included to rectify the problem. In TQM framework, improvement is a job that never finished. This work of continual improvement is typically aided by statistical and logical problem solving tools. Shewhart developed a never-ending approach toward process improvement called the Shewhart Cycle (also known in Japan as the Deming Cycle and most frequently today as the Plan-Do-Check-Act or PDCA Cycle). This approach emphasizes the continuing, never-ending nature of process improvement.

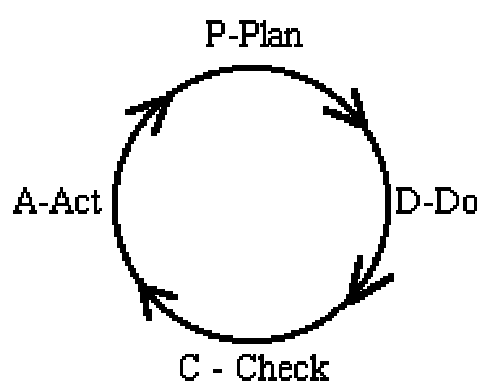

The PDCA cycle is really a simple feedback loop system.

PLAN: A plan is developed to improve a process.

DO: The plan is tested in a small field test.

CHECK: The results of the test are assessed.

ACT: If successful, the plan is implemented.

The improvement process begins again and the cycle is repeated. The repetition of the PDCA cycle, with each cycle producing improvement, leads us to the term continuous improvement.

Clearly, the teaching and learning that take place within a course is a process, albeit a complex one. The product of the process is the learning of the student. Primary team members in the process are the professor and the student. Many other team members also exist in this complex system, including librarians, other faculty members, tutors, lab assistants, and other students. The businesses, industries, and professions served are also team members because they help to identify relevant course content. Maintenance and custodial personnel are team members because they have a direct effect on the quality of the learning environment. The professor, based on his/her experience and expertise, develops the plan for learning and a process that results in student mastery of the course material.

In traditional classrooms, teachers often follow this sequence:

$$
\text { Plan }=======-\rightarrow \text { Teach }=======-7 \text { Test }
$$

The normal curve that usually results stands as testimony to the fact that many students fail to learn at the highest possible level in this system. The TQM alternative is:

\section{Plan $==\rightarrow$ Teach $($ DO $)==\rightarrow$ Check $==\rightarrow$ Revised Teaching $($ ACT $)==\rightarrow$ Test}


In the "check" step, formative (not-for-grade) testing is used to determine which learning some students have missed. Then non-mastered material is re taught in some different way or style. If advisable, the checking and revised teaching can be repeated more than once. Meanwhile students who have mastered the material move to enrichment learning or assist with instruction of those who have not achieved mastery. This system of mastery learning can result in much more complete learning for most students, in effect, a positive movement of the "normal" curve. This improvement in learning is a basic purpose of TQM in the classroom.

\section{5- Self-assessment and benchmarking}

In the effort to be continually better, it is held to be important to know what the "best in class" practices are for a given business sector or activity. Hence, TQM circles also have their strong proponents of benchmarking activities. The emphasis here is on finding out how an organization's techniques compare to the best in the world. Where an organization is behind, every effort is made to quickly emulate the leader's performance, and where and organization's methodology is "state of the art," opportunities for yet another quantum improvement are to be considered.

\section{6- Change to flat organizations" without barriers"}

It is rather standard TQM doctrine that the approach can really only be effective in organizations that are appropriately structured and properly unified in their acceptance of the viewpoint. Hence, There is a strong emphasis in the movement on changing corporate cultures and structures to enable this effectiveness. Proponent of TQM simultaneously emphasize the importance of involving all corporate citizens in TQM activities, beginning with the highest levels of management, and at the same time reducing the number of layers between the "top" and "bottom" of an organization, making it more egalitarian.

The hierarchical organizations of yesterday are still dominant in too many businesses and universities. Such organizations tend to promote individual effort "good enough" to satisfy a supervisor who sometimes knows less about how to achieve quality than those he/she supervises. Cross-department teams can and do promote stronger improvement if they are:

a. Given a clear mission and strong authority.

b. Supported rather than hampered by supervisors.

Support is a major element in the success or failure of TQM. If administrators, supervisors, and department chairpersons support task improvement teams, those teams can generate more motivation and improvement than can otherwise be achieved. If not, TQM cannot achieve its potential. In properly operated TQM programs, administrators and supervisors work diligently at:

a. Insisting on clear visions and missions

b. Coordinating among task or improvement teams

c. Supporting the efforts and authority of improvement teams to the highest possible degree.

These are very critical support actions. Unless administrators and supervisors fulfill them properly, task improvement teams can fail because of this system weakness.

\section{7- Universal responsibility}

As success depends on teamwork, this concept deals with the fact that quality is not only the responsibility of the inspection department but is everyone's responsibility. Quality should be totally pervasive. Every work group in the business should be concerned with seeking ways to improve the quality of their own product or service. This can only be achieved by the cooperation between the different groups and their independent responsibility.

\section{8- Appreciation/ Understanding of Variability}

Providing training in statistics including the basics of describing variation through numerical and graphical means such as Shewhart control chart is a typical early step in TQM programs

\section{9- Defect prevention}


Quality management is a study that eventually leads to a reduction in defects at the initial stages rather than their production.

This defect prevention not only saves money but also saves time. A production process begins with a product specification. Drawings are produced, parts are made and assembled, and the product is delivered to the customer. The cost of rectifying a defect increases by at least a factor of ten as the product moves through each of these stages. In other words defect prevention evaluates the defect in the early stages rather than at the end and by doing this a lot of time and money will be saved.

\section{How TQM in education can implement?}

Research on TQM implementation in the educational sector can be conveniently grouped into four research streams as said by Motwani, Jaideep [2]

1. The first stream deals with the definition of, and overview articles on, quality management in education include a diverse range of topics such as important elements that separate TQM in the educational sector from TQM in other industries, roadblocks to implementing TQM, and comparisons of quality practices among different institutions.

2. The second stream consists of normative studies done mainly by practitioners. These deal with the importance of TQM, both to the overall organization and to functional areas of the organization. Stream 2 also provides normative suggestions for institutionalizing TQM strategies in educational institutions, including a proactive rather than reactive approach, steps for building a TQM system, factors that must be considered in implementing a TQM program in the educational sector, examples of how educational institutions have successfully institutionalized TQM strategies, and the benefits of implementing TQM. This stream covers a medley of studies whose main thrust is to emphasize the importance of TQM. Written largely by practitioners, these studies are all conceptual in approach and without any kind of methodological rigor. However, one cannot dismiss their contributions to the field because the authors, for the most part, speak from field experience.

3. The third research stream is concerned with developing conceptual models for assessing and implementing quality management strategies. Several researchers suggest specific models or steps for implementing the principles of TQM (Brower[3]; Coate[4]; Enthin[5]; Ewell [6]; Feigenbaum[7]; Helms \& Key [8]; Rhodes [9]) or for selecting an effective set of measures for institutions practicing it (Godbey [10]; Marchese [11]). Even though the models/steps suggested by the authors cited are detailed, the main criticism of this stream is that there has been little effort to use existing theory to develop a comprehensive model of TQM in educational institutions.

4. The fourth stream, which can be considered the culmination of all research done in TQM, deals with the assessment and successful implementation of current practices of quality management by educational institutions. Most of the research under this stream, done through field studies, questionnaire surveys, or case studies, illustrates how TQM can create a competitive advantage.

For implementing TQM in education Motwani and Jaideep believes that a five phases approach as follows:

Phase 1. In the first phase, "awareness and commitment," the top management (senior administrators) must develop a complete understanding of what TQM is and how they plan to achieve it. For example, would the university like to start the process at the administration level or in a particular discipline?

Phase 2. Once the understanding is achieved and commitment is made, in the second or "planning" phase of the model, the administration should:

1. Perform an internal quality assessment of the organization to identify strengths and weaknesses, 
2. Provide education to key personnel,

3. Set visions and objectives in writing, and

4. Design a new system.

University administrators should take care to ensure that the organization's culture is suitable to foster TQM and agrees with its values and visions.

Phase 3. In the third, or programming, phase, the administration should

1. Name the process,

2. State purpose through a new quality framework,

3. Provide training to all levels of personnel,

4. Conduct internal and external customer surveys to evaluate the current process and make necessary adjustments,

5. Formulate a quality council to oversee and regulate the TQM process,

6. Perform competitive benchmarking to compare its performance with that of other organizations,

7. Form quality improvement teams, and

8. Establish valid measures and quality indicators for the objectives and goals of the organization.

When naming the process, every effort should be made to avoid associating TQM in the educational field with its use in other industries, because administrators, faculty, and staff view themselves as different from manufacturing employees.

Phase 4. The implementing phase-should include

1. Providing ongoing education and training,

2. Forming new committees, new teams, new departments, or hiring new specialists to help the process as and when required, and

3. Recognizing and rewarding quality improvements.

Recognition can be a valuable tool for improving employee morale, self-interest, and interest in TQM. The reward system, however, must be managed carefully. Remember that you are dealing with a highly educated staff and that monetary rewards can and will be manipulated for personal gain without regard for the institution's well being.

Phase 5. The final, or evaluation, phase of the model should involve annual evaluation of the success or failure of the program. If the program is not achieving its goals, it should be redesigned.

\section{Conclusion:}

TQM is a philosophy and system for continuously improving the higher educational programs, which offered to customers. Now that the technologies of transportation and communication have replaced national economic systems with a global economy, nations and businesses that do not practice TQM can become globally non-competitive rather rapidly. This march towards non-competitiveness can be avoided if citizens are helped to become TQM practitioners. Therefore, the potential benefits of TQM in a university or college are very clear:

1- $\quad$ TQM can help a university or college provide better service to its primary customers-students and employers.

2- The continuous improvement focus of TQM is a fundamental way of fulfilling the accountability requirements common to educational reform.

3- Operating a no-fear TQM system with a focus on continuous growth and improvement offers more excitement and challenge to students and teachers than a "good-enough" learning environment can provide. Therefore, the climate for learning is improved. 


\section{REFERENCES}

1 - Vardeman, S. B. and Jobe, J. M,( 1999), "Statistical Quality Assurance Methods for Engineers", John Wiley \& Sons Inc.

2 -Motwani, Jaideep, Implementing TQM in education: Current efforts and future research directions, Journal of Education for Business. Washington: Nov 1995. Vol. 71, Iss. 2; pg. 60

3 - Brower, M. (1991). The paradigm shifts required to apply TQM and teams in higher education. Readings in Total Quality Management, 485-497.

4 - Coate, L. E. (1990). TQM at Oregon State University. Journal for Quality and Participation, December, 90101.

5 - Enthin, D. H. (1993). Boston: Less than meets the eye. Change, May/June, 28-31.

6 - Ewell, P. T. (1993). Total quality \& academic practice: The idea we've been waiting for? Change, 25, 49-55.

7 - Feigenbaum, A. (1994). Quality education and America's competitiveness. Quality Progress, September, 83-84.

8 - Helms, S., \& Key, C. (1994). Are students more than customers in the classroom? Quality Progress, September, 97-99.

9 - Rhodes, L. A. (1992). On the road to quality. Educational Leadership, 50, 76-80.

10 - Godbey, G. 11993). Beyond TQM: The agile institution. Educational Record, Spring, 37-42.

11 - Marchese, T. (1993). TQM: A time for ideas. Change, 25, 10-13. 